\title{
Assess the Main Factors Affecting the International Marina of Taba Heights at the Gulf of Aqaba, Red Sea, Egypt
}

\author{
Mohamed Hamza Hasan \\ Aquatic Environment Department, Faculty of Fish Resources, Suez University, Suez, Egypt \\ Email: marinehamza@yahoo.com
}

Received October 18, 2013; revised November 23, 2013; accepted December 21, 2013

Copyright (C) 2014 Mohamed Hamza Hasan. This is an open access article distributed under the Creative Commons Attribution License, which permits unrestricted use, distribution, and reproduction in any medium, provided the original work is properly cited. In accordance of the Creative Commons Attribution License all Copyrights @ 2014 are reserved for SCIRP and the owner of the intellectual property Mohamed Hamza Hasan. All Copyright (C) 2014 are guarded by law and by SCIRP as a guardian.

\section{ABSTRACT}

The increase in maritime traffic means that ports have to continuously improve their efficiency. This involves reducing the inactivity caused by adverse conditions that affect its operation and maintenance which includes the sedimentation rate, the shallow depth, water current regimes and tidal cycle. This study examines the hypothesis that these factors could affect Taba Heights international marina. The results showed that the harbor offered very good protection against sediment deposition (rate of sediment deposition ranging from 0.2 to $1.9 \mathrm{mg}^{\circ} \mathrm{cm}^{-2} \cdot \mathrm{day}^{-1}$ ) and currents (two main currents having opposite directions, the first at bearing 261 degree North with mean speed of $3.5 \mathrm{~cm} / \mathrm{sec}$, the second at bearing 85 degree North with mean speed of $4.5 \mathrm{~cm} / \mathrm{sec}$ ), while it had a suitable tidal range $(0.3 \mathrm{~m}$ for neap tidal range and $0.9 \mathrm{~m}$ for spring tidal range). The bathymetric study of the marina area showed deeper water at the approaching channel (3.5 to 4.0 meters deep) and inside the marina (3.0 - 4.0 $\mathrm{m})$ than the surrounding marine areas ( 0.5 to 1.5 meters). The data obtained illustrated that all the investigated factors had limited effect on the operation of Taba Hieghts international marina.

\section{KEYWORDS}

International Marina; Current; Sedimentation Rate; Bathymetry; Tide; Gulf of Aqaba; Red Sea

\section{Introduction}

Ports and maritime services have always played a very important role in the historical and economical development of states. Thus, we need to expand our ability to offer a comprehensive maritime package including facilities for the handling of all types of cargos, passengers, ship repair, bunkering and the positive of other maritime services [1].

Port operations are one of the most important waterdependant activities; therefore, many coastal management programs have specified policies for port development [2]. Although large urban ports are generally under pressure from a variety of stakeholders to integrate non-trade objectives into harbour planning and management [3], their main activity is to provide services to maritime traffic [4].

In recent years, maritime traffic has increased signifi- cantly, which means that ports have continuously improved their facilities and services. Therefore, solutions are sought to minimize problems for users. In particular, ports aim to reduce the inactivity or the decrease in the operation performance caused by adverse environmental conditions which include sediment deposition in the approaching channel and docks, adversely current regimes and decreased depths [5]. Thus, in order to avoid and lighten the influence of adverse factors, we should analyze and diagnose its possible effects.

In the last two centuries, rapidly expanding human population and associated urban development around the world have generated significant impact in coastal marine environment [6]. Among most evident changes to coastline and coast environment, harbours play a pivot role in both economic and ecological reasons [7].

Taba Heights is fast becoming the luxury gateway for 
both land and seafarers. It is the ideal port of call, especially now for seafarers who wish to take a voyage up the Red Sea and cruise the Gulf of Aqaba. Taba Heights marina began to operate at the mid-nineties and granted an International Tourist Marina license in July 2005. The Taba Heights Marina is the first legitimate port of entry in the region. Formerly, in order to sail or cruise Egyptian waters, boats were required to first check in at other, more distant points of entry. Now, there is a more localized port that offers maritime visitors direct access, entry and secure moorings, making the Gulf of Aqaba a much more attractive and appealing destination to sail to.

The International marina of Taba Heights serves in two directions from Egypt to Jordan and Vice versa. The market has steadily grown, with most of the marina traffic consisting of Sinai tourists going to Jordan for day trips to Petra and the Dead Sea. On the other hand, significant growth has also been noted in the number of Jordanians taking advantage of Egypt's natural assets just a short distance from their home country.

The international marina of Taba Heights may be affected as a result of sediment movement or other natural hydrographic conditions. These conditions mainly affect the navigation inside and outside the marina. The main hazard that could occur and affect the marina is sedimentation, which could precipitate inside the marina and approaching channel.

As a result, this work aims to study the current situation of the area, which includes sedimentation rate, currents, tide and bathymetry, to assess the main factors that affect the safety of the marina, navigation, surrounding coastal and marine areas.

\section{Materials and Methods}

\subsection{Study Site}

The Taba Heights Marina's prime position is evidenced by its close distance to neighboring ports:

- Tala Bay Resort and Marina, Aqaba: nine nautical miles

- Royal Yacht Club, Aqaba: 13 nautical miles

Taba Heights Marina is located at the most Northern tip of the Gulf of Aqaba (Figures 1 and 2). The shoreline in front and around of the marine is smooth and regular, this structure cause no eddies or pockets could affect the water circulation. It was designed as an inland marina with an approximately 11,500 square meters of water area, with depths of between 2.5 and 4 meters near the main docks. The marina has a wide approaching channel with about 50 meters length, the depth of the channel ranged between 3 and 4 meters deep.

\subsection{Bathymetric Survey}

A depth survey was carried out for all the marine area inside and around the marina. An ecosounder was used to measure the depth at certain points taken by GPS. The points were taken at 5 meters intervals parallel to and perpendicular on the shore to ensure all the different depths in the area are included. The data collected was drawn using Surfer program.

\subsection{Tide}

Two tide cages (water leveling recorders) were putted in the marine area in front of the marina for six weeks, one

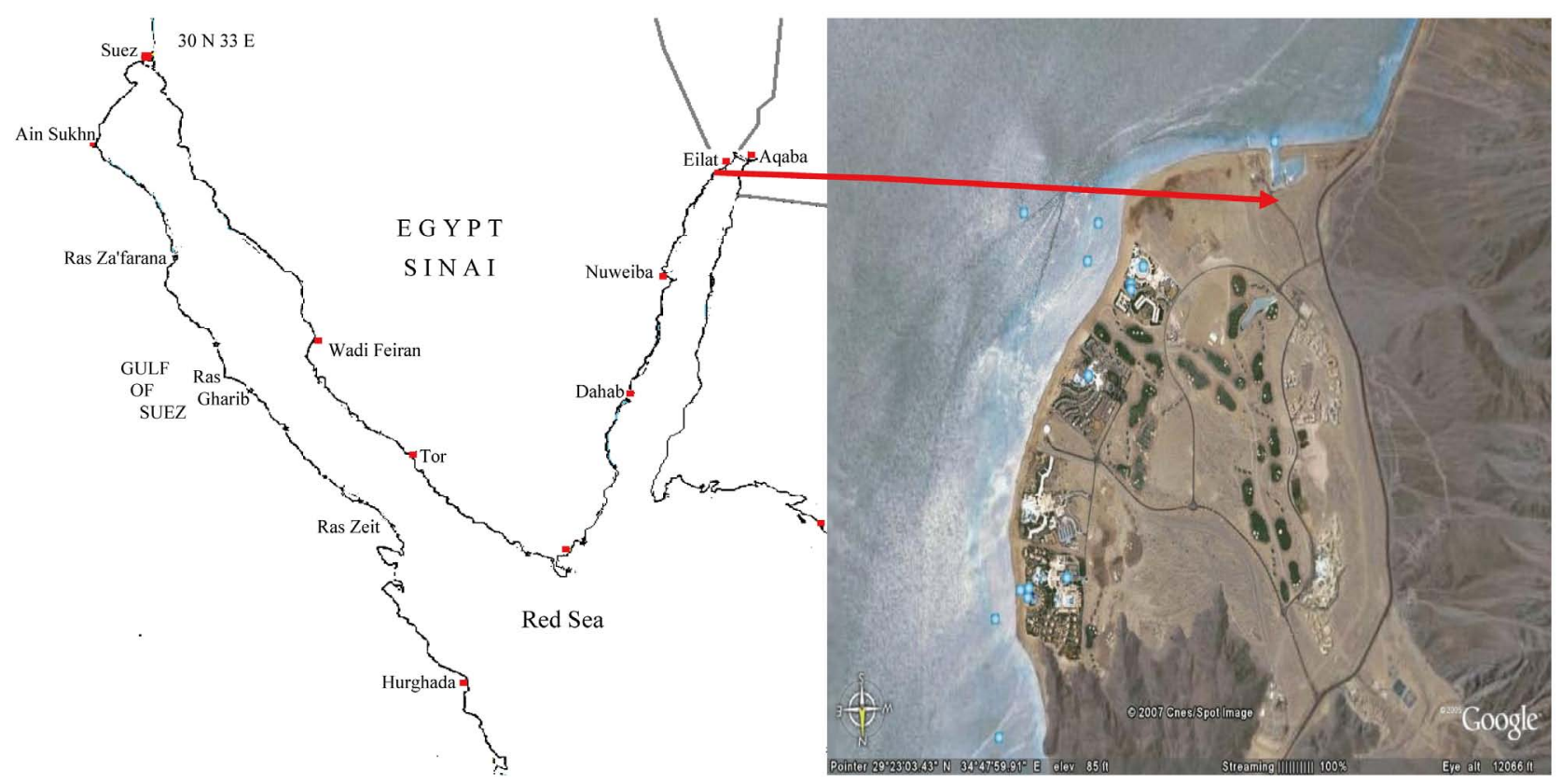

Figure 1. Map showing the study area. 


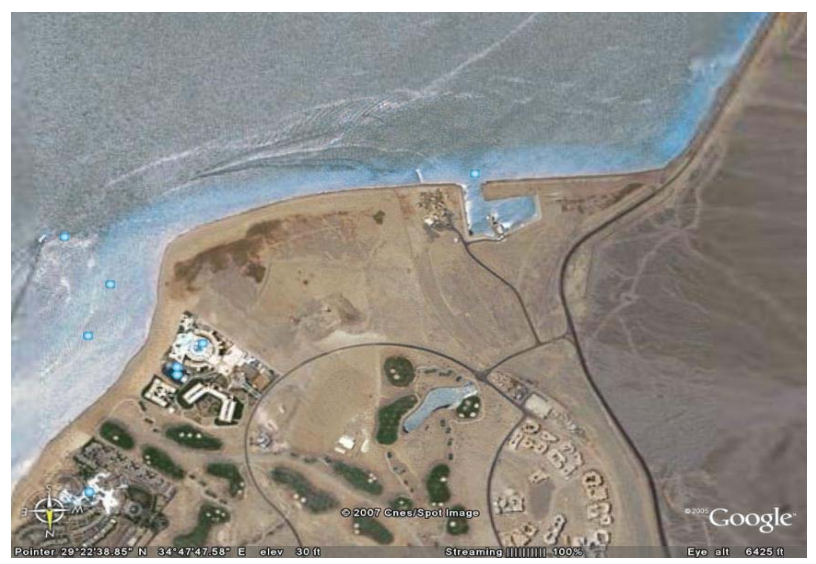

Figure 2. Satellite image showing the location of the Taba Heights international marina in the Gulf of Aqaba, Red Sea, Egypt.

on five meter depth and the other on eight meters depth. The data obtained was analyzed and the different tidal cycles and the tidal range were identified.

\subsection{Water Current}

The data of two current meters were collected, one at $5 \mathrm{~m}$ and the other at $16 \mathrm{~m}$ deep. The current meters were placed at the open water in front of the approaching channel for 45 days.

\subsection{Sedimentation Rate}

Sedimentation rate was assessed using an experimental design (Rogers et al., 1994). Sediment traps consisting of straight sided plastic jars with a height of $24 \mathrm{~cm}$ and a diameter of $8 \mathrm{~cm}$ (height to diameter ratio was approximately 3:1) were deployed in groups of three at nine different locations, around the marina, under the buoys at the deep water, south and north of the approaching channel at the coastal area, the center of the approaching channel, and at the entrance of the marina.

All the traps were placed at a depth ranged from 3 to 5 meters. The sediment traps were left in site for 20 days and were replaced after they were retrieved on two occasions resulting in three replicates overtime. The traps were capped underwater carefully brought upright to the surface and transported to the laboratory.

Each trap was allowed to stand for one hour, after which the sea water in the trap was siphoned off until approximately $100 \mathrm{ml}$ remained to avoid disturbing the sediments that settled on the bottom. The settled contents were then removed and washed several times with distilled water to remove salts. The supernatant distilled water was also siphoned. The settled sediment were allowed to dry at $60^{\circ} \mathrm{C}$ till reaching a constant weight. The sedimentation rate was expressed as mg dry weight/ $\mathrm{cm}^{2} /$ day.

\section{Result}

To assess the factors could affect the operation of the Taba Heights international marina, a full survey was carried out include bathymetry, tide, currents and sedimentation rate and sediment movements inside and around the marina.

\subsection{Bathymetric Survey}

The marina's bathymetric survey showed deeper water at the approaching channel and inside the marina than the surrounding marine areas (Figure 3 ). The data obtained are summarized as follows:

1. The depth at the approaching channel is uniform, ranged from 3.5 to 4.0 meters deep along the channel and the entrance of the marina.

2. Inside the marina, the depth retain the same value (3.0 - $4.0 \mathrm{~m}$ ), it decreases to range from 2.5 to 3.0 meters at the docks. The side of the marina has shallow depths ranged from 0.5 to 1.5 meters.

3. The surrounding marine area is divided into two parts, first is the shallow area (adjacent to the coast), which had a shallow depth ranged from 0.5 meters near the coast gradually increase to $1.0,2.0$ and 2.5 meters heading seaward. There is nearly uniformly depth at the south and north of the marina, interrupted with the Approaching channel which is much deeper (3.5 - $4.0 \mathrm{~m}$ ). Second, the deeper water begin at 60 meters away from the shoreline. This area characterized by a sudden fall in depth to 6 meters followed by sharply increase in depth to 12 meters after 100 meters away from the shoreline.

\subsection{Tide and Tidal Cycle}

The tidal regimes at the marina area are semidiurnal. There are two clearly defined high tides and two low

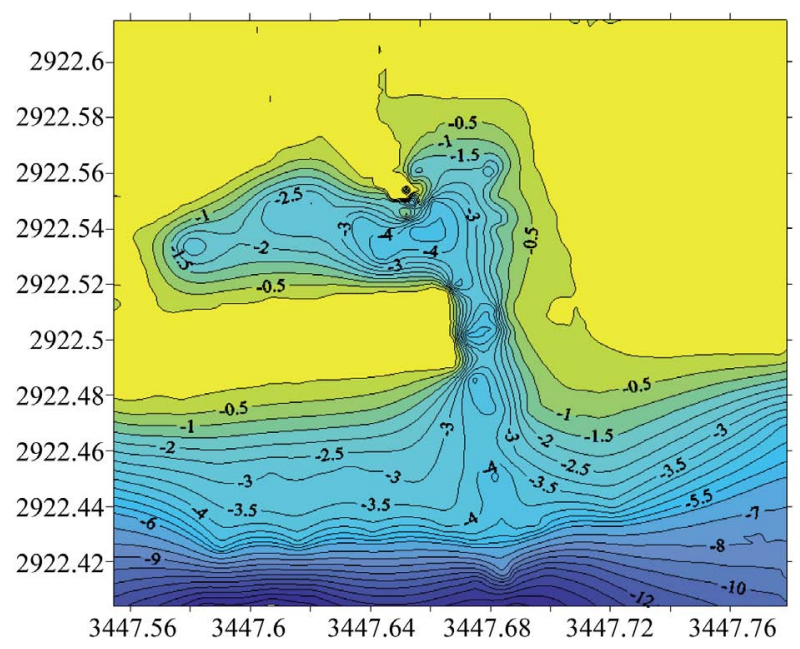

Figure 3. The bathymetric chart for Taba Heights international marina. 
tides everyday. Table 1 shows the main tidal parameters, which were obtained by analyzing sea level time series collected with a tidal gauge. The tidal cycle was measured at the marina area, to identify the tidal range which includes the HHW, the LLW and the difference in water level. This serves in identifying the secure navigational depth (Table 1).

The Neap HHW recorded 0.9 m, while the Neap LLW recorded $0.6 \mathrm{~m}$. The Neap tidal range was $0.3 \mathrm{~m}$. The spring HHW recorded $1.2 \mathrm{~m}$, while the Spring LLW recorded $0.3 \mathrm{~m}$. The Spring tidal range was $0.9 \mathrm{~m}$. Table 1 showed the tidal cycle at the investigated area during the Spring (new and Full moon) and Neap (crescent) tides.

The data revealed several facts, summarized in the following points:

1. There are two types of tides at the project area:

a) Neap Tide: which occur for about 22 days of the month, thus it is the dominant tidal pattern. And at this kind of tide the water will have the following measurements:

- HHW Neap is $0.9 \mathrm{~m}$.

- LLW Neap is $0.6 \mathrm{~m}$.

- The tidal range at the neap tide is $0.3 \mathrm{~m}$.

b) Spring tide: which occur for about 7 to 8 days of the month, thus it is the minor tidal pattern. And at this kind of tide the water will have the following measurements:

- HHW spring is $1.2 \mathrm{~m}$.

- LLW spring is $0.3 \mathrm{~m}$.

- The tidal range at the spring tide is $0.9 \mathrm{~m}$.

\subsection{Current Regimes at the Area}

The data collected from the current meter placed on 5 meters deep was not reliable since the high sporadic data obtained from this instrument. While we depended mainly on the data collected from the deeper current meter that was putted on 16 meters deep. The current directions were very intermingled and spreading. Analysis of the data showed two main current directions, the first and the most frequent one was at bearing 261 degree North with a mean speed of $3.5 \mathrm{~cm} / \mathrm{sec}$., the other less frequent current was nearly at the opposite direction, at bearing 85

Table 1. The tidal measurements at Taba heights international marina.

\begin{tabular}{cc}
\hline Parameter & Water height $(\mathrm{m})$ \\
\hline HHW Neap & 0.9 \\
LLW Neap & 0.6 \\
Neap tidal range & 0.3 \\
HHW spring & 1.2 \\
LLW Spring & 0.3 \\
Spring tidal range & 0.9 \\
\hline
\end{tabular}

degree North with mean current speed of $4.5 \mathrm{~cm} / \mathrm{sec}$ (Figure 4).

Translating the data obtained from the current meters and plotted at the previous current rose, we could find that:

The most frequent current stream (261 degree North) is coming from the south of the marina heading to the north with a speed of $3.5 \mathrm{~cm} / \mathrm{sec}$ (Figure 5).

2) The less frequent current stream (85 degree North) is the retarding current coming from the north of the marina and heading south with a speed of $4.5 \mathrm{~cm} / \mathrm{sec}$ (Figure 5).

\subsection{Sedimentation Rate}

The data obtained showed slight sedimentation rate at all traps. Rate of sediment deposition ranged from 0.2 near shore right to the marina to $1.9 \mathrm{mg} \cdot \mathrm{cm}^{-2} \cdot$ day $^{-1}$ at the middle of the channel (Table 2). According to Rogers's classification the area is not subjected to any sedimentation.

\section{Discussion}

The increase in maritime traffic between Egypt and Jordan through the international marina of Taba heights means that it has to continuously improve its facilities and ability to accept these boats. An analysis of the given data shows that the marina offer excellent shelter against all adverse environmental conditions.

Since this study represents a first application of whole conditions affecting Taba heights international marina, comparison with other results are not possible.

Functionally, efficiency and ability of the marina to operate properly, the different factors such as currents,

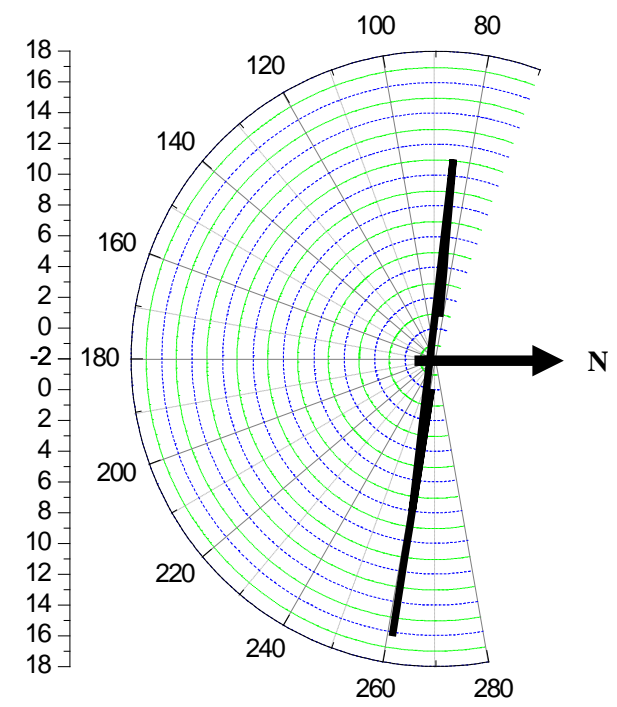

Figure 4. The current rose of Taba heights international marina. 


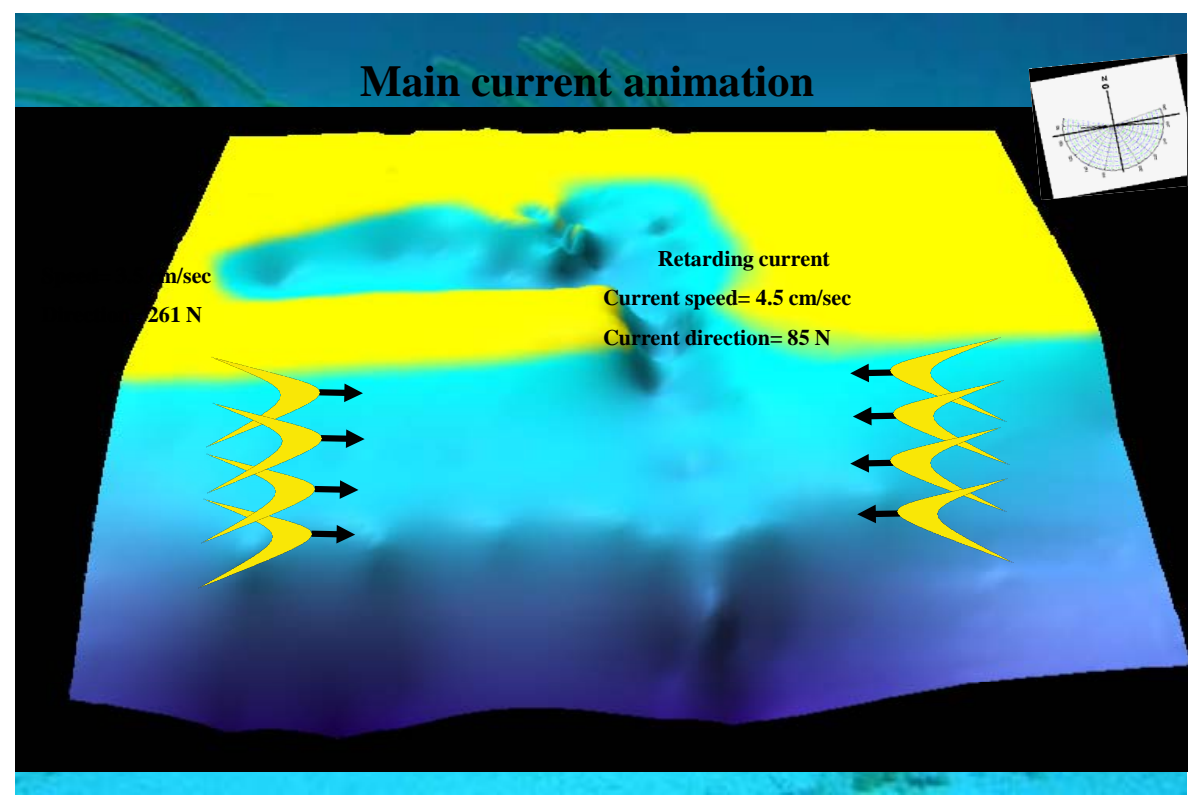

Figure 5. The most and less frequent current streams at Taba heights international marina.

tide, depth and sediment deposition must be identified, and their identification needs a whole system approach.

The impact of dynamic conditions of the water is relatively important to the proper use of the marina [8]. The basic indicators include the changes of depths, the highest and lowest levels of intertidal cycle, current regimes and sediment depositions.

\subsection{Bathymetry}

The marina was constructed as inland marina, and thus it needed an approaching channel for the boat navigation in and out. The bathymetric analysis of the marina area showed uniformly of depth at both the approaching channel and the entrance of the marina and the approaching channel is still much deeper than the surrounding areas. This indicates that both the marina and approaching channel retain their depth, which mean that there is no sediment deposition in the area.

\subsection{Tide}

In order to identifying the secure navigational depth, tide measurements at the project area were carried out. The tidal measures indicated that the sea water level permit the safe navigation in and out of the marine even in the Spring tidal range, because the depth at the marina and approaching channel ranged between 3 and $4 \mathrm{~m}$ deep, and thus the height of the water column will be as follows:

- At the neap tide (22 days of the month): the tidal range is $30 \mathrm{~cm}$ thus the minimum water column ranged from $2.7 \mathrm{~m}$ to $3.7 \mathrm{~m}$ depth.

- At the spring tide (7 days of the month): the tidal range is $90 \mathrm{~cm}$, thus the minimum water column ranged from 2.10 to $3.10 \mathrm{~m}$ depth.

At both cases the depth is safe for all navigational purposes.

\subsection{Current}

Analysis the current data revealed that the current direction is parallel to the shoreline, which in turn is smooth without any eddies or irregular areas (bays, heads, etc.). These make the current steady and smoothly moving in front of the cost, and cause no sediment precipitation. The current speed at the marina area is relatively high, which prevent any sediment precipitations as a result of current slowdown. The current measurement at the marina area showed two main directions opposite to each other and recording low speed variation, which lead to no sediment accumulation at the area.

\subsection{Sedimentation Rate}

In spite the fact the shallowness of an area promotes high turbidity due to resuspension of bottom sediment by waves [9], the rate of sediment deposition at the marina ranged from 0.2 to $1.9 \mathrm{mg} \cdot \mathrm{cm}^{-2}$. day ${ }^{-1}$. According to [10] sedimentation rate divided into the following categories:

a) $<7 \mathrm{mg} \cdot \mathrm{cm}^{-2} \cdot \mathrm{day}^{-1}$ areas not subjected to any sedimentation.

b) 7 - $20 \mathrm{mg} \cdot \mathrm{cm}^{-2} \cdot$ day $^{-1}$, implies moderate sedimentation rate.

c) $>20 \mathrm{mg} \cdot \mathrm{cm}^{-2} \cdot$ day $^{-1}$, imply sever impacts.

The study of sediment movements around and in the marina was carried out to answer the question, whether there is sediment filling inside the marina and/or the 


\section{approaching channel or not?}

The sedimentation rates inside and around the marina were compared with the international standards of high, moderate and low sedimentation rates signified by Rogers [10].

The sediment trap methods is an efficient method for an accurate determination and calculation of sediment deposition and movement at any particular place. And hence we could map the sediment movement at the area by using the trap method.

Discussing the sediment deposition at Table 2, several facts could be realized:

1) The sediment deposition in all traps was very low, where there was no sediment deposition.

2) The sediment deposition rate at the area around and inside the marina was found in normal range that will not lead to filling or precipitation inside the marina or approaching channel.

3) Only the fifth, sixth and seventh traps recorded a slightly higher sedimentation rate than the other traps, which recorded $1.2,1.4$ and $1.9 \mathrm{mg} \cdot \mathrm{cm}^{-2} \cdot$ day $^{-1}$, which also represent no sediment deposition at any area measured.

\section{Conclusions}

The analysis of the different environmental factors at the area of the International marina of Taba heights gives a good view about the situation at the area and subsequently concludes what must be done to protect the marina, maintain its efficiency and save navigation. All the elements studied revealed that there was no sediment precipitation inside the marina or at the approaching channel.

Tidal measures indicated that the sea water level permitted the safe navigation in and out of the marina even in the Spring tidal range. The depth at the marina and approaching channel ranged between 3 and $4 \mathrm{~m}$ deep, and

Table 2. Sedimentation rates at the different traps at the area.

\begin{tabular}{clc}
\hline $\begin{array}{c}\text { Trap } \\
\text { no. }\end{array}$ Position of the trap & $\begin{array}{c}\text { Sedimentation rate } \\
\left(\mathrm{mg} \cdot \mathrm{cm}^{-2} \cdot \mathrm{day}^{-1}\right)\end{array}$ \\
\hline 1 & Near shore right to the marina & 0.2 \\
2 & At the entrance of the marina (to the left) & 0.5 \\
3 & At the entrance of the marina (at the middle) & 0.5 \\
4 & At the entrance of the marina (at the middle) & 0.6 \\
5 & At the middle of the channel & 1.2 \\
6 & Little right to the channel & 1.4 \\
7 & Near shore left of the marina & 1.9 \\
8 & At the buoys, beginning of the channel. & 0.5 \\
9 & Off shore-right to the marina. & 0.9 \\
\hline
\end{tabular}

thus it was safe for all navigational purposes.

The bathymetric survey revealed that both the marina and approaching channel retained their depth. This is indicated by the uniformly of depth at both the approaching channel and the entrance of the marina.

Analysis of the current data revealed that the current direction was parallel to the shoreline, which in turn was smooth without any eddies or irregular areas (bays, heads, etc.). These made the current steady and smoothly moving in front of the coast, and caused no sediment precipitation.

As a result of the previous data, it could be concluded that constructing any artificial obstacles at the marine area will greatly affect the current speed and direction, which will lead to highly sediment accumulation in the area.

\section{REFERENCES}

[1] C. F. Wooldridge, C. McMullen and V. Vicki Howe, "Environmental Management of Ports and Harbors Implementation of Policy through Scientific Monitoring," Marine Policy, Vol. 23, No. 4, 1999, pp. 413-425 http://dx.doi.org/10.1016/S0308-597X(98)00055-4

[2] M. J. Hershman, "Seaport Development and Coastal Management Programs: A National Overview,” Coastal Management, Vol. 27, No. 2-3, 1999, pp. 271-291. http://dx.doi.org/10.1080/089207599263866

[3] P. Yarnell, "Port Administration and Integrated Coastal Management under the Canada Marine Act in Vancouver, British Columbia, Canada,” Coastal Management, Vol. 27, No. 4, 1999, pp. 343-354. http://dx.doi.org/10.1080/089207599263758

[4] D. Gonzalez-Marco, J. Pau Sierra, J. Fernandez de Ybarra and A. Sanchez-Arcilla, "Implications of Long Waves in Harbor Management: The Gijon Port Case Study,” Ocean \& Coastal Management, Vol. 51, No. 2, 2008, pp. 180201. http://dx.doi.org/10.1016/j.ocecoaman.2007.04.001

[5] A. K. Otta, "Harbour Excitation Due to a Coast-Parallel Current," Proceedings of the 28th International Conference on Coastal Engineering, Wales, 2002, pp. 13031314.

[6] A. M. Smith, A. C. Wood, M. F. Liddy, A. E. Shears and C. I. Fraser, "Human Impacts in an Urban Port: The Carbonate Budget, Otago Harbour, New Zealand,” Estuarine, Coastal and Shelf Science, Vol. 90, No. 2, 2010, pp. 7379. http://dx.doi.org/10.1016/j.ecss.2010.07.004

[7] P. Vassallo, C. Paoli, G. Schiavon, G. Albertelli and M. Fabiano, "How Ecosystems Adapt to Face Disruptive Impact? The Case of a Commercial Harbor Benthic Community,” Ecological indicator, Vol. 24, 2013, pp. 431438

[8] R. L. Soulsby, "Dynamics of Marine Sands. A Manual for Practical Applications,” Thomas Telford Publications, Thomas Telford Services Ltd; London, 1997, p. 249.

[9] L. Fishelson, "Marine Reserves along the Sinai Peninsula 
(Northern Red Sea)," Helgoländer Meeresuntersuchungen, Vol. 33, No. 1-4, 1980, pp. 624-640.

http://dx.doi.org/10.1007/BF02414785

[10] C. S. Rogers, "Responses of Coral Reefs and Reef Or- ganisms to Sedimentation,” Marine Ecology Progress Series, Vol. 62, 1990, pp. 185-202.

http://dx.doi.org/10.3354/meps062185 